\title{
The effect of diets containing different proportions of butterfat and maize oil on plasma lipids and aortic atherosis in rabbits
}

\author{
By J. H. MOORE \\ Hannah Dairy Research Institute, Ayr \\ (Received ro Fune 1968-Accepted 15 August 1968)
}

\begin{abstract}
I. Seven groups of male rabbits (thirteen to fifteen per group) were given ad lib. a diet consisting of 80 parts of a low-fat basal ration to which were added 20 parts of fat in the form of butterfat, maize oil or various mixtures of the two.

2. After 40 weeks, samples of blood were taken and the animals were killed. The concentrations of total cholesterol and phospholipid in the plasma and the fatty acid compositions of the plasma cholesteryl esters and phospholipids were determined. The degree of atheromatous degeneration was determined in the aortas.

3. Little aortic atherosis was observed in the rabbits given the diets containing 0,10 and $r 2 \%$ butterfat, but as the butterfat content of the diet was increased above $12 \%$, pronounced increases occurred in the extent of atheromatous degeneration of the aorta. The concentration of cholesterol in the plasma increased progressively as the butterfat content of the diet was increased and the maize oil content was decreased. There was an inverse curvilinear relationship between the degree of aortic atherosis and the phospholipid:cholesterol ratio in the plasma.

4. The concentration of linoleic acid in the plasma cholesteryl esters was inversely related to the concentration of cholesterol in the plasma, and the concentration of linoleic acid in the plasma phospholipids was inversely related to the concentration of phospholipids in the plasma. There was a positive linear relationship between the stearic:palmitic acid ratio and the linoleic: oleic acid ratio in the plasma phospholipids.
\end{abstract}

Moore \& Williams (1964a) observed elevated levels of plasma cholesterol and extensive atheromatous degeneration of the aorta in rabbits given diets containing $20 \%$ butterfat. Little or no aortic atherosis was observed in rabbits given diets in which the $20 \%$ butterfat had been replaced by $20 \%$ maize oil. When rabbits were given a diet containing 10\% butterfat and 10\% maize oil, the degree of aortic atherosis was not significantly different from that observed in rabbits given the diet containing $20 \%$ maize oil. It was of interest to determine to what extent the dietary maize oil could be replaced by butterfat before atheromatous degeneration of the aorta began to occur. Therefore, the extent of aortic atherosis and the concentrations of blood lipids have been investigated in groups of rabbits given a series of diets containing different proportions of butterfat and maize oil. The results of this investigation are now reported.

\section{EXPERIMENTAL}

\section{Rabbits, diets and procedure}

The rabbits used in this study were 105 New Zealand White males, all of the same strain, obtained at the age of 6 months from a local breeder. The animals were housed individually in metal metabolism cages fitted with wire screens. For a short period until they became accustomed to their surroundings the animals were given a commercial rabbit diet. The rabbits were then randomly divided into seven groups of 
fifteen each and were given the various experimental diets for a period of 40 weeks. Throughout the experiment, food and water were given ad lib.

The basal diet was similar to that described by Moore \& Williams (r964a) and consisted (parts by weight) of wheat starch (Procea Nutrex Adcol Ltd, London, W r) I6.3, sucrose 10.0, casein (lactic acid casein; Glaxo Research Ltd, Greenford) 25.0, Solkafloc (grade BW 40 ; Johnsen, Jorgensen and Wettre Ltd, London, EC 4) $19^{\circ} \circ$, methyl cellulose (Celacol M. 450; J. M. Steel and Co. Ltd, London, WC 2) $1 \cdot 0$, potassium acetate 2.5 , magnesium oxide 0.5 , sodium chloride 0.7 , choline chloride 0.5 , salt mixture $4 \cdot 0$, and vitamin mixture 0.5 , making 80 parts in all. The compositions of the salt and vitamin mixtures have been given by Moore \& Williams (1964a). To 80 parts of this low-fat basal diet were added 20 parts of fat in the form of butterfat, maize oil or various mixtures of the two as shown in Table I. The maize oil was obtained from Brown and Polson Ltd, London, WC I and the butterfat was prepared as described by Moore \& Williams ( $1964 a$ ) from butter obtained from Wilts United Dairies, Chard, Somerset. It should be noted that these experimental diets contained no added cholesterol.

During the experiment, the weights of individual rabbits and the total weights of food consumed by the various groups of rabbits were recorded. After 40 weeks on the experimental diets, samples of blood were taken from the marginal ear veins of the rabbits into heparinized tubes and immediately afterwards the animals were killed by a blow on the head. As rapidly as possible thereafter, the aorta, extending from the heart to the point of division into the two common iliac arteries, was removed from each rabbit.

\section{Treatment of tissues and method of analysis}

After the removal of adventitious fatty tissues, the aortas were fixed in $4 \%(\mathrm{w} / \mathrm{v})$ formaldehyde in $0.9 \%(\mathrm{w} / \mathrm{v})$ sodium chloride saturated with calcium carbonate. Each aorta was then stained with Sudan IV $(0.05 \%, \mathrm{w} / \mathrm{v}$, in ethanol-acetone-water, $35: 35: 30, \mathrm{v} / \mathrm{v} / \mathrm{v})$. The degree of atheromatous degeneration of the intimal surface of each aorta was then assessed by the technique of Moore \& Williams (I964a), account being taken of the area covered and the intensity of the Sudan IV staining of the atheromatous lesions. Each aorta was compared with the 'standard' atheromatous aorta referred to previously (Moore \& Williams, I964a). The lipids were extracted from the samples of plasma by the method of Nelson \& Freeman (I959). The total cholesterol and phospholipid contents of the lipid extracts were determined by methods described previously (Moore \& Doran, I962; Moore \& Williams, 1964b). The fatty acid compositions of the plasma cholesteryl esters and phospholipids were determined by the methods given in detail by Moore \& Williams, I963, 1964c) except that the gas-liquid chromatography was carried out with an instrument fitted with dual-flame ionization detectors (Perkin-Elmer Ltd, Beaconsfield, Bucks.). The fatty acid compositions of the experimental diets were determined as described by Moore \& Williams (1963). 


\section{RESULTS}

The numbers of rabbits in each group that survived the experiment, the linoleic acid contents of the experimental diets, the weights of rabbits at the beginning and end of the experiment and the mean food intakes for each group are given in Table $\mathrm{I}$. During the experiment, one rabbit died in each of groups 2,4 and 7 and two in each

Table I. Number of rabbits in each group, contents of maize oil, butterfat and linoleic acid in the experimental diets, weights of rabbits at the beginning and end of the experiment and food intakes during the experiment

\begin{tabular}{|c|c|c|c|c|c|c|c|c|}
\hline & Group I & Group 2 & Group 3 & Group 4 & roup 5 & roup 6 & Iroup 7 & observ \\
\hline $\begin{array}{l}\text { No. of rabbits/ } \\
\text { group at end } \\
\text { of expt }\end{array}$ & I3 & 14 & I5 & I4 & I 5 & 13 & I 4 & - \\
\hline $\begin{array}{l}\text { Maize oil content } \\
\text { of diet }(g / 100 g)\end{array}$ & 0 & 2 & 4 & 6 & 8 & Io & 20 & - \\
\hline $\begin{array}{l}\text { Butterfat content } \\
\text { of diet }(\mathrm{g} / \mathrm{/} 00 \mathrm{~g})\end{array}$ & 20 & 18 & 16 & 14 & 12 & 10 & 0 & - \\
\hline $\begin{array}{l}\text { Linoleic acid } \\
\text { content of diet } \\
(\mathrm{g} / \mathrm{1} 00 \mathrm{~g})\end{array}$ & $0 \cdot 25$ & $1 \cdot 27$ & $2 \cdot 32$ & $3 \cdot 3^{6}$ & $4: 37$ & $5 \cdot 44$ & 10.6 & - \\
\hline $\begin{array}{l}\text { Weight of rabbits } \\
\text { at beginning of } \\
\text { expt }(\mathrm{kg})\end{array}$ & $2 \cdot 98$ & 3.09 & 3.01 & 2.90 & $2 \cdot 93$ & $2 \cdot 85$ & $3 \cdot 13$ & 0.15 \\
\hline $\begin{array}{l}\text { Weight of rabbits } \\
\text { at end of expt (kg) }\end{array}$ & 3.60 & $3 \cdot 74$ & $3 \cdot 67$ & 3.51 & $3 \cdot 66$ & $3 \cdot 54$ & $3 \cdot 85$ & 0.15 \\
\hline $\begin{array}{l}\text { Daily dry-matter } \\
\text { intake (g/rabbit) }\end{array}$ & 95 & 96 & 96 & 94 & 93 & 95 & 96 & 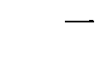 \\
\hline
\end{tabular}

Table 2. Degrees of aortic atherosis and concentrations of total cholesterol and phospholipids in the plasma of the rabbits at the end of the experiment. Mean values with their standard errors.

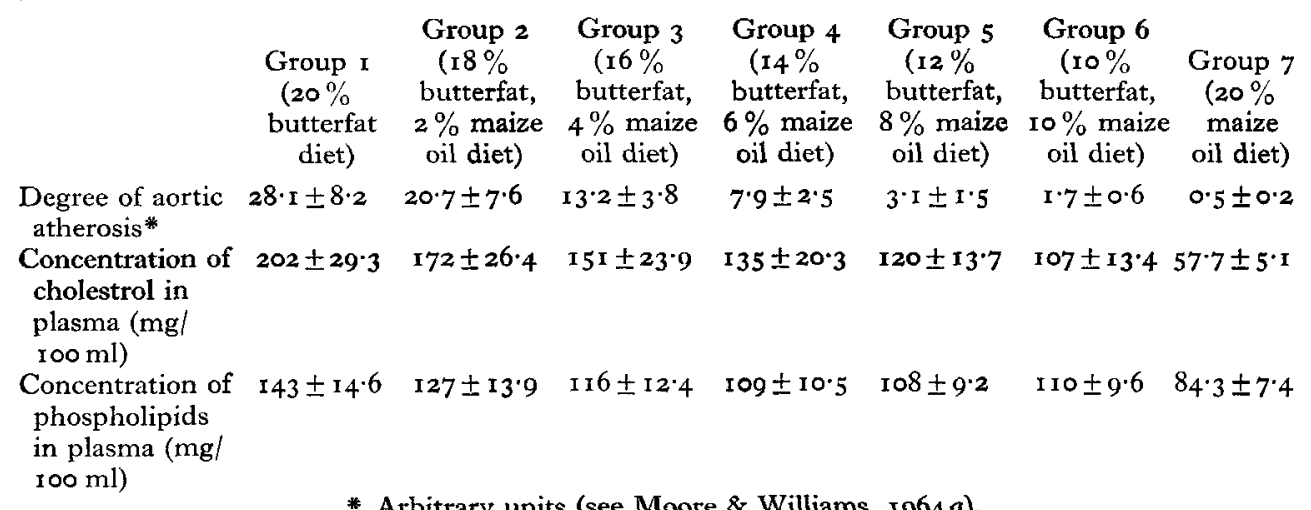

of groups $I$ and 6. Post-mortem examination at the local Veterinary Investigation Centre of the Ministry of Agriculture, Fisheries and Food revealed that these deaths were caused either by 'middle-ear' disease or enteritis. The gains in weight of the animals during the experiment were very similar in all groups, as were the mean food 
intakes. The degrees of aortic atherosis and the concentrations of total cholesterol and phospholipid in the plasma of the rabbits at the end of the experiment are given in Table 2. Histological examination of the aortas revealed that the type of atheromatous lesion was identical in all groups of rabbits. Degeneration was confined to the intimal layer and there were extensive depositions of lipid material between the internal elastic membrane and the endothelial surface. This lipid material appeared to be present

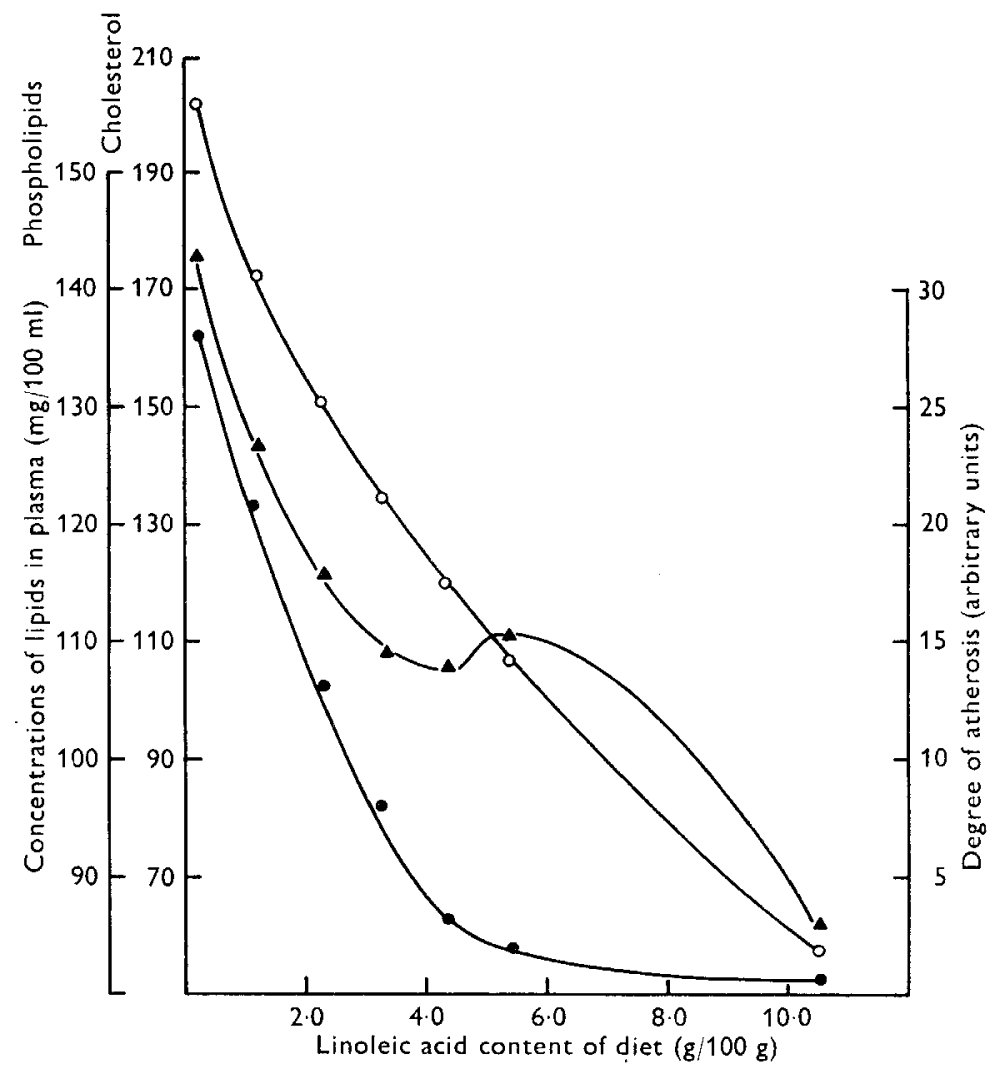

Fig. I. Relationships between the linoleic acid content of the diet and the concentration of cholesterol in the plasma (O), the concentration of phospholipids in the plasma $(\boldsymbol{\Delta})$ and the degree of aortic atherosis $(0)$ in experimental rabbits.

either extracellularly as fine droplets scattered throughout the ground substance or intracellularly as accumulations in lipid-laden phagocytes. A detailed description of this type of atheromatous lesion has been given by Moore \& Williams (1964a). There were marked differences in the extent of atheromatous degeneration in the groups of rabbits given the various diets. As in previous experiments (Moore \& Williams, I964a; Moore, 1967 ) severe aortic atherosis was observed in the rabbits given the diet containing $20 \%$ butterfat (group I), whereas little or no atherosis was observed in the rabbits given the diet containing $20 \%$ maize oil (group 7 ). In fact no aortic atherosis was detected in ten of the fourteen rabbits in this group. The replacement of the dietary butterfat by increasing proportions of maize oil resulted in a progressive 
decrease in the degree of aortic atherosis and there appeared to be an inverse curvilinear relationship between the linoleic acid content of the diet and the degree of aortic atherosis (Fig. I). The high concentration of cholesterol in the plasma of the rabbits in group I was similar to the values observed in previous experiments (Moore \& Williams, $1964 a$ ) in which rabbits were given diets containing $20 \%$ butterfat. The concentration

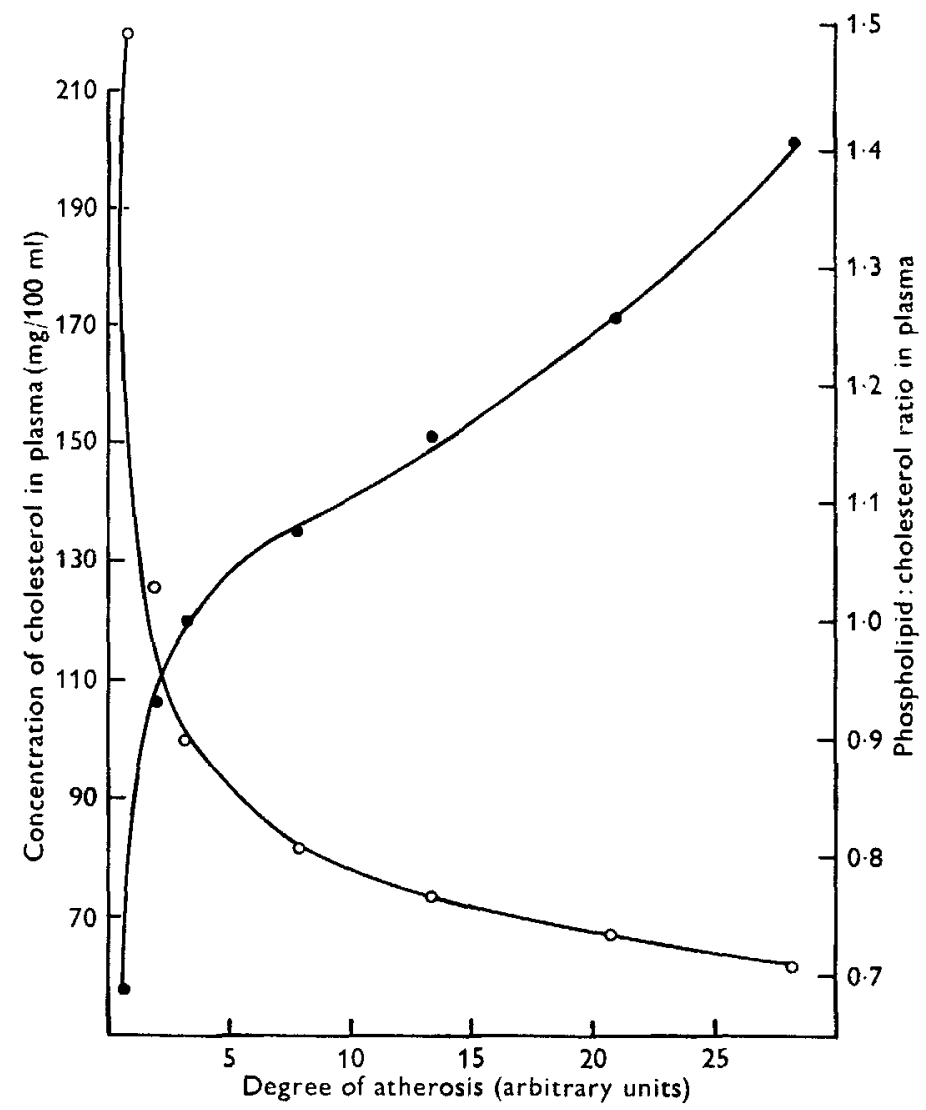

Fig. 2. Relationships between the degree of aortic atherosis and the concentration of cholesterol in the plasma (O) and the phospholipid:cholesterol ratio in the plasma $(O)$ of experimental rabbits.

Table 3. Fatty acid compositions (weight percentages of the total) of the cholesteryl esters in the plasma of the rabbits. Mean values with their standard errors

\begin{tabular}{|c|c|c|c|c|c|c|c|c|}
\hline Fatty acid & $\begin{array}{c}\text { Group I } \\
\text { (20\% } \\
\text { butterfat } \\
\text { diet) }\end{array}$ & $\begin{array}{c}\text { Group } 2 \\
\text { (18\% } \\
\text { butterfat, } \\
2 \% \text { maize } \\
\text { oil diet) }\end{array}$ & $\begin{array}{l}\text { Group } 3 \\
\text { ( } 6 \% \% \\
\text { butterfat, } \\
4 \% \text { maize } \\
\text { oil diet) }\end{array}$ & $\begin{array}{c}\text { Group } 4 \\
\text { (I4\% } \\
\text { butterfat, } \\
6 \% \text { maize } \\
\text { oil diet) }\end{array}$ & $\begin{array}{l}\text { Group } 5 \\
\text { (12\% } \\
\text { butterfat, } \\
8 \% \text { maize } \\
\text { oil diet) }\end{array}$ & $\begin{array}{l}\text { Group } 6 \\
\text { (10\% } \\
\text { butterfat, } \\
\text { 10 } \% \text { maize } \\
\text { oil diet) }\end{array}$ & $\begin{array}{l}\text { Group } 7 \\
\text { (20\% } \\
\text { maize } \\
\text { oil diet) }\end{array}$ & $\begin{array}{c}\text { SE of a } \\
\text { mean of I } 4 \\
\text { observations }\end{array}$ \\
\hline Palmitic & $20 \cdot 1$ & 18.9 & 17.4 & $15 \cdot 7$ & $15 \cdot 3$ & $15 \cdot 2$ & $14 \cdot 5$ & 0.57 \\
\hline Palmitoleic & $4 \cdot I$ & 3.9 & $3 \cdot 6$ & $2 \cdot 04$ & $2 \cdot 0$ & $2 \cdot 8$ & $2 \cdot 3$ & 0.14 \\
\hline Stearic & $6 \cdot 1$ & $5 \cdot 5$ & $4^{-9}$ & $4 \cdot 7$ & 4.9 & $5 \cdot 2$ & $5 \cdot 5$ & 0.55 \\
\hline Oleic & $46 \cdot 5$ & $42 \cdot 5$ & $37 \cdot 6$ & $36 \cdot 7$ & $32 \cdot 0$ & $27 \cdot 6$ & $22 \cdot 1$ & $2 \cdot 33$ \\
\hline Linoleic & 19.7 & 25.5 & $32 \cdot 8$ & $37 \cdot 8$ & $42 \cdot 5$ & $44: 7$ & $49^{\circ} 6$ & $2 \cdot 15$ \\
\hline Arachidonic & 0.9 & 0.9 & $I \cdot I$ & 0.8 & 1.0 & $I \cdot O I$ & $I \cdot 42$ & 0.16 \\
\hline 9 & & & & & & & Nutr & $23, I$ \\
\hline
\end{tabular}


of plasma cholesterol decreased markedly as the maize oil content of the diet was increased and the butterfat content was decreased. There was an inverse curvilinear relationship between the concentration of cholesterol in the plasma and the linoleic acid content of the diet (Fig. I). The variation in the concentration of plasma phospholipids with changes in dietary composition was somewhat more complex (Fig. I). As the linoleic acid content of the diet was progressively increased from 0.25 to $3.4 \%$

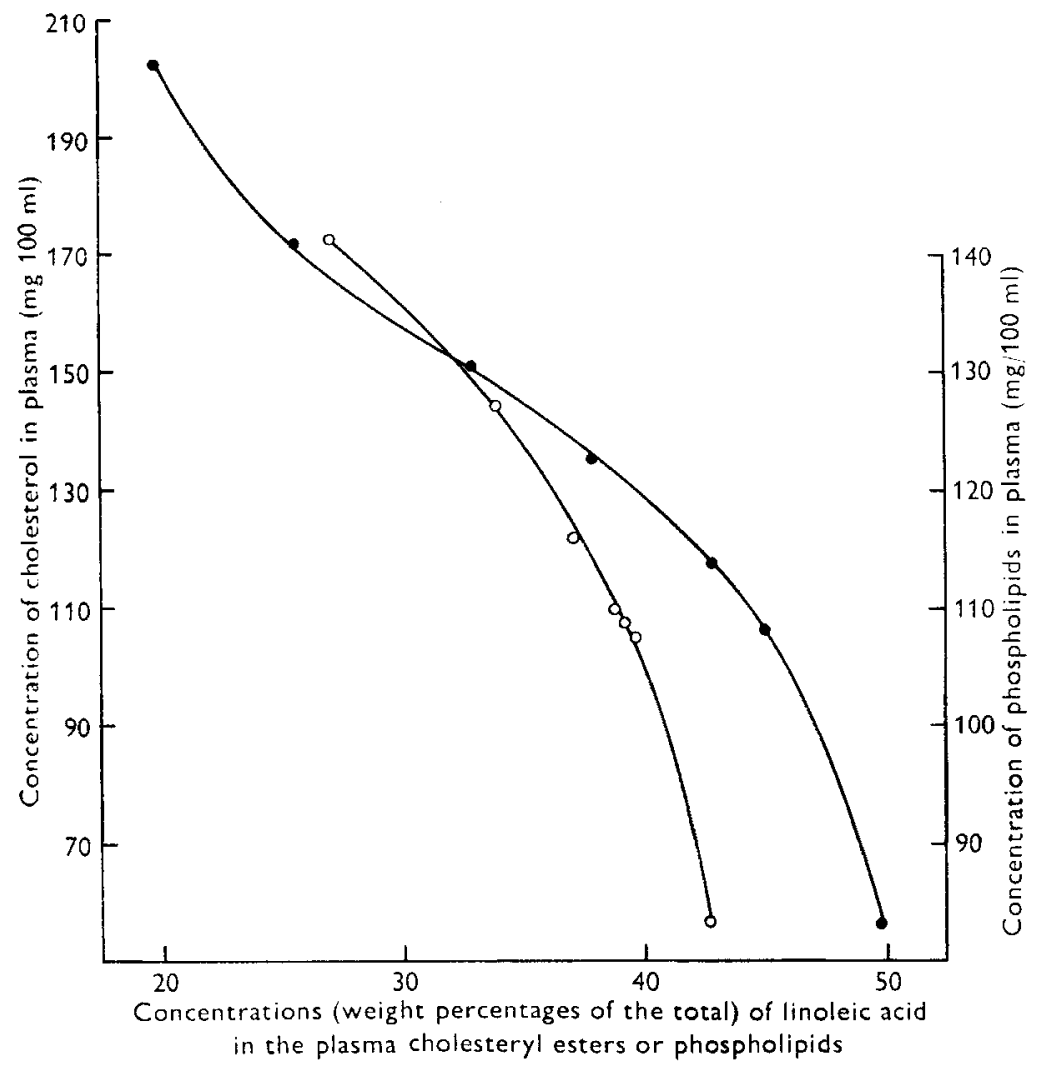

Fig. 3. Relationships between the concentration of linoleic acid in the plasma cholesteryl esters and the concentration of cholesterol in the plasma ( $)$, and between the concentration of linoleic acid in the plasma phospholipids and the concentration of phospholipids in the plasma (O) of experimental rabbits.

there was a gradual decrease in the concentration of plasma phospholipids. No further decrease in the concentration of plasma phospholipids occurred when the linoleic acid content of the diet was increased from 3.4 to $5.4 \%$. However, the concentration of plasma phospholipids decreased to a low level when the linoleic acid content of the diet was increased from 5.4 to $10.6 \%$. The sigmoid curve shown in Fig. 2 was obtained when the degrees of aortic atherosis were plotted against the concentrations of cholesterol in the plasma. Also shown in Fig. 2 is the curve relating the degree of aortic atherosis to the phospholipid: total cholesterol ratio in the plasma.

The fatty acid compositions of the cholesteryl esters in the plasma of the rabbits given the various experimental diets are shown in Table 3. The concentration of 
linoleic acid in the plasma cholesteryl esters increased progressively as the butterfat in the diet was successively replaced by maize oil. As the concentration of linoleic acid in the plasma cholesteryl esters increased, the concentration of oleic acid decreased. The linoleic acid content of the diet had little effect on the concentrations of stearic and arachidonic acids in the plasma cholesteryl esters but the concentration of palmitic acid appeared to decrease as the linoleic acid content of the diet was increased from 0.25 to $3.4 \%$. The relationship between the concentration of linoleic acid in the plasma cholesteryl esters and the concentration of total cholesterol in the plasma is shown in Fig. 3.

Table 4. Fatty acid compositions (weight percentages of the total) of the phospholipids in the plasma of the rabbits. Mean values with their standard errors

\begin{tabular}{|c|c|c|c|c|c|c|c|c|}
\hline Fatty acid & $\begin{array}{c}\text { Group I } \\
\text { (20\% } \\
\text { butterfat, } \\
\text { diet) }\end{array}$ & $\begin{array}{c}\text { Group } 2 \\
\text { (1 } 8 \% \\
\text { butterfat, } \\
2 \% \text { maize } \\
\text { oil diet) }\end{array}$ & $\begin{array}{l}\text { Group } 3 \\
\text { (16\% } \\
\text { butterfat, } \\
4 \% \text { maize } \\
\text { oil diet) }\end{array}$ & $\begin{array}{l}\text { Group } 4 \\
\text { (I4\% } \\
\text { butterfat, } \\
6 \% \text { maize } \\
\text { oil diet) }\end{array}$ & $\begin{array}{l}\text { Group } 5 \\
\text { (12\% } \\
\text { butterfat, } \\
8 \% \text { maize } \\
\text { oil diet) }\end{array}$ & $\begin{array}{c}\text { Group } 6 \\
\text { (10\% } \\
\text { butterfat, } \\
\text { 10\% maize } \\
\text { oil diet) }\end{array}$ & $\begin{array}{c}\text { Group } 7 \\
(20 \% \\
\text { maize } \\
\text { oil diet })\end{array}$ & $\begin{array}{c}\text { SE of a } \\
\text { mean of } 14 \\
\text { observations }\end{array}$ \\
\hline Palmitic & $24 \cdot 6$ & $23 \cdot 4$ & $22: 4$ & $21 \cdot 6$ & $21 \cdot 0$ & $2 I \cdot 8$ & r 9.6 & 0.50 \\
\hline Palmitoleic & 0.6 & 0.6 & $1 \cdot 0$ & 0.6 & 0.7 & 0.5 & 0.3 & 0.23 \\
\hline Stearic & I $8 \cdot I$ & I 9.3 & 19.9 & 20.4 & 20.9 & $20 \cdot 1$ & $20 \cdot 2$ & 0.61 \\
\hline Oleic & $21 \cdot 7$ & I $7 \cdot \mathbf{I}$ & $13 \cdot 2$ & $12 \cdot I$ & 10. 5 & $12 \cdot 3$ & $10 \cdot 1$ & 0.43 \\
\hline Linoleic & 27.0 & $33 \% 7$ & $36 \cdot 8$ & $39^{\circ} \mathrm{I}$ & $39^{\circ} 6$ & $38 \cdot 8$ & $42 \cdot 8$ & 0.53 \\
\hline $\begin{array}{l}\text { Eicosa- } \\
\text { trienoic }\end{array}$ & 0.9 & 0.5 & 0.6 & 0.3 & 0.6 & 0.4 & 0.4 & 0.07 \\
\hline Arachidonic & $4 \cdot 8$ & $3 \cdot 2$ & 3.8 & $3 \cdot 2$ & $4 \cdot 3$ & 3.4 & 3.4 & 0.36 \\
\hline $\begin{array}{l}\text { Docosa- } \\
\text { pentaenoic }\end{array}$ & 0.7 & 0.5 & 0.6 & 0.8 & $1 \cdot 0$ & 0.9 & 0.8 & 0.13 \\
\hline $\begin{array}{l}\text { Docosa- } \\
\text { hexaenoic }\end{array}$ & 0.7 & 0.5 & 0.6 & 0.5 & 0.8 & 0.7 & 0.8 & 0.13 \\
\hline
\end{tabular}

The fatty acid compositions of the phospholipids in the plasma of the rabbits given the different experimental diets are shown in Table 4. The concentration of linoleic acid in the plasma phospholipids increased as the linoleic acid content of the diet was increased from 0.25 to $3.4 \%$. Further increases in the linoleic acid content of the diet up to $5.4 \%$ produced no changes in the concentration of linoleic acid in the plasma phospholipids, but there was a small increase in the linoleic acid content of the plasma phospholipids when the linoleic acid content of the diet was increased to $10.6 \%$. The relationship between the concentration of linoleic acid in the plasma phospholipids and the concentration of phospholipids in the plasma is also shown in Fig. 3. It should be noted that the overall increase in the concentration of linoleic acid in the plasma phospholipids (from 27 to $43 \%$ ) was noticeably less than the overall increase in the concentration of linoleic acid in the plasma cholesteryl esters (from 20 to $50 \%$ ). Variations in the concentrations of linoleic, oleic, palmitic and stearic acids in the plasma phospholipids appeared to be related and there was a positive rectilinear relationship between the linoleic:oleic acid ratio and the stearic:palmitic acid ratio in the plasma phospholipids (Fig. 4). The concentrations of the $\mathrm{C}_{20}$ and $\mathrm{C}_{22}$ polyunsaturated fatty acids in the plasma phospholipids did not vary to any great extent as the linoleic acid content of the diet was increased. 


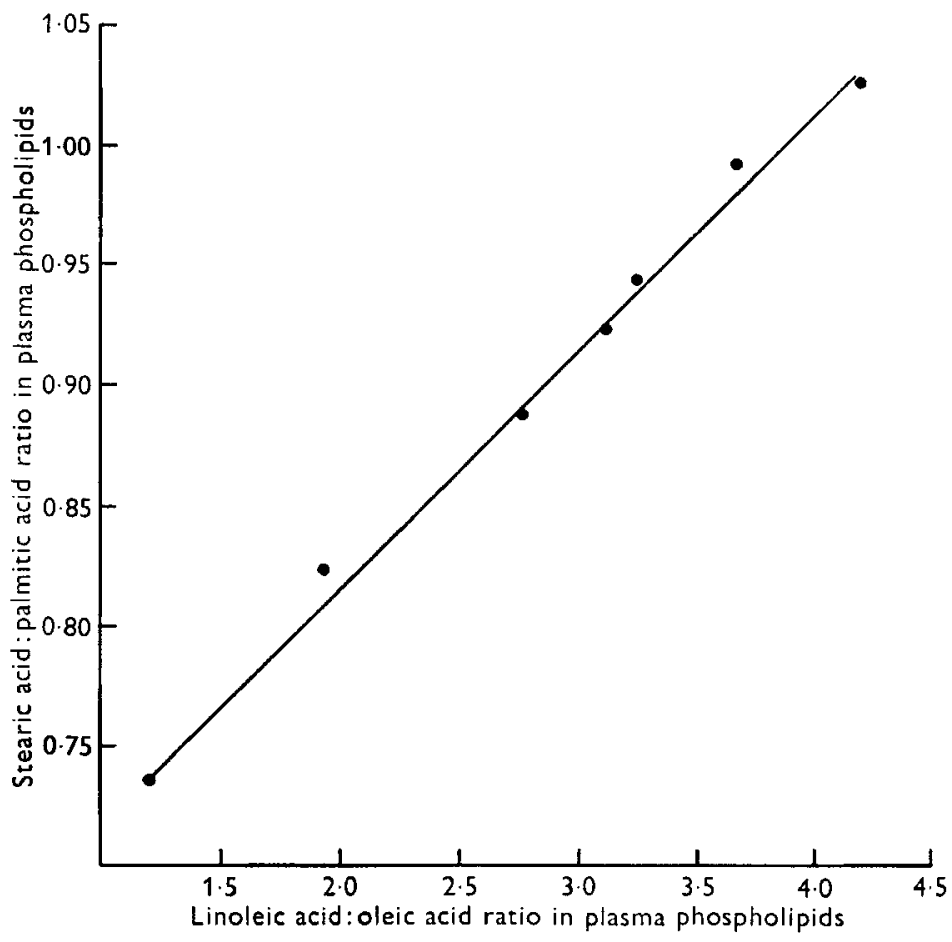

Fig. 4. Relationship between the stearic acid:palmitic acid ratio and the linoleic acid:oleic acid ratio in the plasma phospholipids of experimental rabbits.

\section{DISCUSSION}

As in previous experiments (Moore \& Williams, I964a), the rabbits given the diet containing $20 \%$ butterfat developed extensive atheromatous degeneration of the aorta, whereas little or no aortic atherosis was observed in the rabbits given the diets containing $20 \%$ maize oil or $10 \%$ maize oil and 10\% butterfat. Little aortic atherosis was observed in the rabbits given the diet containing $8 \%$ maize oil and $12 \%$ butterfat, but further replacement of maize oil by butterfat in the diet resulted in a pronounced increase in the degree of aortic atherosis (Fig. I). It would appear, therefore, that under the conditions of the experiment, marked increases in the extent of atheromatous degeneration of the aorta occurred when the linoleic acid content of the diet decreased below $4.0 \mathrm{~g} / \mathrm{I} 00 \mathrm{~g}$. Since the gross energy value of the diets used in this experiment was $530 \mathrm{kcal} / \mathrm{roO} \mathrm{g}$, this level of dietary linoleic acid is equivalent to $0.75 \mathrm{~g} / 100 \mathrm{kcal}$. Moore \& Williams (I964a) showed that rabbits also developed extensive aortic atherosis when they were given a low-fat, high-starch diet, and that when the dietary starch was partly replaced by maize oil, the degree of aortic atherosis was decreased. It was concluded, therefore, that the atherogenic properties of a particular diet may be determined by its polyunsaturated fatty acid:calorie ratio, irrespective of whether the major portion of the calories is supplied by fat or as carbohydrate (Moore $\&$ Williams, 1964a). A rigorous test of this hypothesis would be to carry out an experiment similar to the one now described, but in which there was a gradual replacement of the starch 
contained in a low-fat, high-starch diet by isocaloric amounts of maize oil. It would then be of interest to determine whether, under these dietary conditions, the degree of aortic atherosis would have increased substantially when the linoleic acid content of the diet was also decreased below $0.75 \mathrm{~g} / 100 \mathrm{kcal}$.

The successive replacement of the butterfat in the diet by maize oil resulted in a gradual decrease in the concentration of cholesterol in the plasma (Fig. I) and there was a positive curvilinear relationship between the concentration of cholesterol in the plasma and the degree of aortic atherosis (Fig. 2). This relationship was such that the degree of aortic atherosis did not increase appreciably until the concentration of cholesterol in the plasma had risen above $120 \mathrm{mg} / 100 \mathrm{ml}$. In an earlier study, Moore \& Williams $(1964 b)$ could find no overall relationship between the degree of aortic atherosis and the concentration of cholesterol in the plasma of rabbits given a variety of atherogenic diets containing different amounts of fat or starch. Nevertheless, in the rabbits given high-fat diets, there was a positive correlation between the concentration of cholesterol in the plasma and the degree of aortic atherosis (Moore \& Williams, $1964 b$ ), which is in agreement with the present findings. In this earlier study (Moore \& Williams, $1964 b$ ) it was observed that, in general, the degree of aortic atherosis was most closely correlated with the phospholipid: free cholesterol ratio in the plasma of the rabbits given the various atherogenic diets. The degree of aortic atherosis began to increase when the phospholipid:free cholesterol ratio decreased below $3 \cdot 0$, but when the ratio decreased below $2 \cdot 0$ the degree of aortic atherosis increased markedly. Unfortunately, the concentrations of free and esterified cholesterol were not determined separately in the experiment now described, but it is clear from Fig. 2 that the degree of aortic atherosis began to increase when the phospholipid: total cholesterol ratio in the plasma decreased below 0.9 . There was a pronounced increase in the degree of aortic atherosis when the phospholipid: total cholesterol ratio decreased below 0.8 . Since free cholesterol accounts for about one-third of the total cholesterol in the plasma of rabbits given purified diets of the type used in these experiments (Moore \& Williams, 1966), it may be calculated that phospholipid: total cholesterol ratios of 0.9 and 0.8 are equivalent to phospholipid:free cholesterol ratios of $2 \cdot 7$ and $2 \cdot 4$ respectively. The results shown in Fig. 2 thus appear to be in agreement with the findings of the previous investigation (Moore \& Williams, $1964 b$ ).

As the linoleic acid content of the diet was increased there were progressive increases in the concentration of linoleic acid in the plasma cholesteryl esters (Table 3 ) and the concentration of linoleic acid in the plasma cholesteryl esters was inversely related to the concentration of total cholesterol in the plasma (Fig. 3). In the plasma of man, Lewis (1958), Wright, Pitt \& Morton (1959) and Swell, Schools \& Treadwell (1962 $a, b$ ) have observed inverse relationships between the concentration of cholesterol and the concentration of polyunsaturated fatty acids in the cholesteryl esters. The metabolic implications of such relationships have been discussed by Moore \& Williams ( $1965 a$ ). There was an inverse relationship between the concentration of linoleic acid in the plasma phospholipids and the concentration of phospholipids in the plasma (Fig. 3), but an increase in the linoleic acid content of the diet from 3.4 to $5.4 \%$ resulted in no change either in the linoleic acid concentration in the plasma phospholipids or in the 
concentration of phospholipids in the plasma. This somewhat unexpected finding requires further elucidation since it may throw some light on the factors that control the phospholipid:cholesterol ratio in the plasma and hence the relationship between plasma lipid composition and atheromatous degeneration of the aorta. If the composition of the plasma phospholipids reflects the rates of synthesis of different phospholipids in the liver, then it is possible that a change in the linoleic acid content of the diet might alter the proportions of phosphatidyl choline and phosphatidyl ethanolamine in the plasma. Moore \& Williams $(1965 b)$ have shown that the phosphatidyl choline in rabbit liver contains higher concentrations of linoleic acid than does the liver phosphatidyl ethanolamine. The somewhat complicated curve for total plasma phospholipid concentration shown in Fig. 2 might be due to variations in the proportions of the individual phospholipid fractions. The interrelationships between the various fatty acids in the plasma phospholipids shown in Fig. 4 may be explained by the fact that there is now considerable evidence for the existence of specific intramolecular associations between individual fatty acids in the glycerophosphatides isolated from a variety of tissues (Harris, Robinson \& Getz, 1960; Collins, I963; Moore, Williams \& Westgarth, I965; Van Deenen, Van Golde \& Demel, 1966). For instance, in the phosphatidyl choline of rabbit plasma, it would appear that stearic acid in the $\alpha$-position tends to be associated with linoleic acid in the $\beta$-position and palmitic acid in the $\alpha$-position tends to be associated with oleic acid in the $\beta$-position (Moore et al. 1965).

The experimental rabbits were housed at the National Institute for Research in Dairying, Shinfield, and the author is grateful to the Director, Professor Sir Ronald Baskett, for his co-operation. The author is also grateful to Miss J. Carrinci, Miss A. Wallace, Dr R. C. Noble and Mr E. V. Ruby for their assistance. This study was supported by a grant from the Butter Information Council.

\section{REFERENCES}

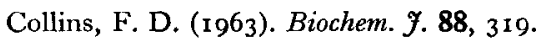

Harris, P. M., Robinson, D. S. \& Getz, G. (1960). Nature, Lond. 188, 742.

Lewis, B. (1958). Lancet ii, 71 .

Moore, J. H. (1967). Br. F. Nutr. 21, 207.

Moore, J. H. \& Doran, B. M. (I962). Biochem. F. 84, 506.

Moore, J. H. \& Williams, D. L. (1963). Can. F. Biochem. Physiol. 4I, 182 I.

Moore, J. H. \& Williams, D. L. (1964a). Br. F. Nutr. 18, 253.

Moore, J. H. \& Williams, D. L. (1964b). Br. F. Nutr. r8, 43 I.

Moore, J. H. \& Williams, D. L. (1964c). Biochem. biophys. Acta 84, 4I.

Moore, J. H. \& Williams, D. L. (1965a). Br. F. Nutr. 19, 407.

Moore, J. H. \& Williams, D. L. $(1965 b)$. Biochim. biophys. Acta 98, 137.

Moore, J. H. \& Williams, D. L. (1966). Br. F. Nutr. 20, 57 I.

Moore, J. H., Williams, D. L. \& Westgarth, D. R. (1965). Biochim. biophys. Acta 106, I45.

Nelson, G. J. \& Freeman, N. K. (1959). F. biol. Chem. 234, I375.

Swell, L., Schools, P. E. Jr \& Treadwell, C. R. (1962 a). Proc. Soc. exp. Biol. Med. 109, 682.

Swell, L., Schools, P. E. Jr \& Treadwell, C. R. (1962b). Proc. Soc. exp. Biol. Med. r11, 48.

Van Deenen, L. L. M., Van Golde, L. M. G. \& Demel, R. A. (1966). Biochem. F. 98, r78.

Wright, A. S., Pitt, G. A. J. \& Morton, R. A. (I959). Lancet ii, 594. 